\title{
Lymph node ratio is a better prognosticator than lymph node status for gastric cancer: A retrospective study of 138 cases
}

\author{
WEI-JUAN ZENG ${ }^{1}$, WEN-QIN HU ${ }^{2}$, LIN-WEI WANG ${ }^{1}$, SHU-GUANG YAN ${ }^{2}$, JIAN-DING LI ${ }^{3}$, \\ HAO-LIANG ZHAO ${ }^{4}$, CHUN-WEI PENG ${ }^{1}$, GUI-FANG YANG ${ }^{1}$ and YAN LI ${ }^{1}$ \\ ${ }^{1}$ Departments of Oncology and Pathology, Zhongnan Hospital of Wuhan University, \\ Hubei Key Laboratory of Tumor Biological Behaviors and Hubei Cancer Clinical Study Center, Wuhan, Hubei 430071; \\ ${ }^{2}$ Department of Surgery, Heji Hospital Affiliated to Changzhi Medical College, Changzhi, Shanxi 046000; \\ ${ }^{3}$ Department of Medical Imaging, The First Affiliated Hospital of Shanxi Medical University, Taiyuan, \\ Shanxi 030001; ${ }^{4}$ Department of General Surgery, Shanxi University Hospital, Taiyuan, Shanxi 046000, P.R. China
}

Received March 9, 2013; Accepted September 13, 2013

DOI: $10.3892 / \mathrm{ol} .2013 .1615$

\begin{abstract}
To study the clinical significance of lymph node ratio (LNR) in gastric cancer (GC), this study analyzed 613 patients with GC who underwent surgical resection. Of 613 patients with GC, 138 patients who had $>15$ lymph nodes (LNs) resected and radical resection were enrolled into the final study. All major clinicopathological data were entered into a central database. LNR was defined as the ratio of the number of metastatic LNs to the number of removed LNs. In order to determine the best cut-off points for LNR, the log-rank test and X-tile were used. LNR was then substituted for lymph node status $(\mathrm{pN})$ in the 7 th American Joint Committee on Cancer tumor-node-metastases (TNM) staging system and this was defined as the tumor-node ratio-metastases (TRM) staging system. Pearson's correlation coefficient (r) was used to study the correlations among the number of removed LNs, $\mathrm{pN}$ and LNR. The Kaplan-Meier survival curve was used to study the survival status, and the log-rank test and Cox proportional hazards model were used to identify the independent factors for survival. Receiver operating characteristic curve analysis was used to determine the predictive value of the parameters. By the time of last follow-up (median follow-up period, 38.3 months; range, 9.9-97.7 months), the median overall survival (OS) was 23.9 months [95\%
\end{abstract}

Correspondence to: Professor Yan Li, Departments of Oncology and Pathology, Zhongnan Hospital of Wuhan University, Hubei Key Laboratory of Tumor Biological Behaviors and Hubei Cancer Clinical Study Center, 169 Donghu Road, Wuhan, Hubei 430071, P.R. China

E-mail: liyansd2@163.com

Professor Jian-Ding Li, Department of Medical Imaging, The First Affiliated Hospital of Shanxi Medical University, 85 South Jiefang Road, Taiyuan, Shanxi 030001, P.R. China

E-mail: cjr.jianding@vip.163.com

Key words: gastric cancer, lymph node ratio, prognosis confidence interval (CI), 18.8-29.0 months]. The 1-, 2-, 3- and 5-year survival rates were 76.8, 57.2, 50.0 and $46.4 \%$, respectively. The cut-off points were $0,0.5$ and $0.8(\mathrm{R} 0, \mathrm{LNR}=0 ; \mathrm{R} 1$, $\mathrm{LNR} \leq 0.5$; R2, $0.5>\mathrm{LNR} \leq 0.8$; and R3, LNR >0.8). Univariate and multivariate analyses revealed that both LNR and $\mathrm{pN}$ were independent prognostic factors for GC. LNR could better differentiate OS in patients than LN. In addition, the TRM staging system was better at predicting the clinical outcomes than the TNM staging system, and LNR was better than $\mathrm{pN}$. In conclusion, LNR was a better prognosticator than $\mathrm{pN}$ for GC.

\section{Introduction}

Gastric cancer (GC) is the fourth most common malignancy with $\sim 1$ million patients diagnosed with GC worldwide per year, and the second leading cause of cancer-related mortality worldwide with 800,000 fatalities per year (1), though the prevalence and mortality of GC have gradually decreased (2). In China, 0.4 million new cases of GC and 0.3 million fatalities occurred each year, making it the third leading cause of cancer-related mortality (3). In addition, the outcome of GC remains poor with a 5-year survival rate of only $\sim 20-25 \%$ (4).

Accurate prediction of the prognosis of patients with GC is crucial, as surgery is the most important therapeutic approach (5). It helps to define which patients with GC should receive secondary treatments, such as chemotherapy and/or radiotherapy, which are largely dependent on clinical staging $(6,7)$.

The prognosis of GC is closely related to the tumor stage, including the depth of tumor invasion, lymph node status and distant metastases (8-10). The most commonly used staging system of GC is proposed by the American Joint Committee on Cancer (AJCC) and is known as the AJCC tumor-node-metastases (TNM) staging system. In 2010, the 7th edition of the AJCC gastric cancer staging manual was ascertained, resulting in much controversy (11). Certain studies confirmed that the 7th AJCC TNM staging system was superior to the 6th AJCC TNM staging system (12-14), 
while other studies confirmed the 6th was better for prognostic stratification $(15,16)$.

In recent years, lymph node ratio (LNR), defined as the ratio of the number of metastatic lymph nodes (LNs) to the number of removed LNs, has gained increasing attention in researches because of its lymph node status (pN) in AJCC TNM staging system (17-19). However, the analytical methods of these studies were commonly the same and no in depth investigations have been conducted.

In this study, GC patients with radical resection and extended lymphatic resection were selected, as $\mathrm{R} 0$ resection with D2 lymphadenectomy is regarded as the standard surgical technique in Eastern Asian countries (7). Comprehensive analytical methods were used to evaluate whether LNR was a superior prognosticator compared with $\mathrm{pN}$ for GC.

\section{Patients and methods}

Patients. This retrospective study initially consisted of 613 patients with GC who underwent resection from three tertiary referral hospitals from January 2004 to August 2011. All the clinicopathological information was available, including demographic variables, underlying co-morbidities, surgical modality, lab and image study information, pathological reports, pre- and postoperative therapies, and follow-up information. Among these patients with GC, only those who had $>15 \mathrm{LNs}$ resected and radical resection were enrolled into the final study. Patients who had palliative resection, $\leq 15 \mathrm{LNs}$ resected and incomplete follow-up information were excluded, as this method was more suitable for those patients with $>15$ LNs resected. In total, 138 patients were enrolled into the final study.

The patients were followed up every 3 months during the first 2 years after surgery, every 6 months during the third postoperative year and every year thereafter. All the follow-up information was entered into a database.

Tumor-node-ratio-metastases (TRM) staging system. For defining the TRM staging system, two recognized methods were used to determine the best cut-off points for LNR. One was the commonly used cut-off approach using the log-rank test, the other was X-tile as reported by Wang et al (17). X-tile determines the optimal cut-off points of LNR by taking LNR as a continuous variable. Compared with the commonly used cut-off approach, X-tile controls for the inflated type I error problem and minimizes information loss. LNR was then substituted for $\mathrm{pN}$ in the 7th AJCC TNM staging system to generate the TRM staging system as the $\mathrm{N}$ classification of the 7th AJCC TNM staging system is thought to be superior (13).

Statistical analysis. All data were analyzed using SPSS 17.0 statistical software package (SPSS, Inc., Chicago, IL, USA). Pearson's correlation coefficient (r) was used to study the correlations among the number of removed LNs, $\mathrm{pN}$ and LNR. The Kaplan-Meier survival curve was used to study the survival status, and the log-rank test and Cox proportional hazards model were used to identify the independent factors for survival. Receiver operating characteristic (ROC) curve analysis was used to determine the predictive value of the parameters. Two-sided $\mathrm{P}<0.05$ was considered to indicate a statistically significant difference.

\section{Results}

Characteristics of patients. Among 613 GC patients who had undergone resection from three tertiary referral hospitals between January 2004 and August 2011, 138 were enrolled into the final study. By the time of the last follow-up (May 31, 2012), 76 mortalities had occurred. The median number of removed LNs was 21 (range 16-47). The median age of patients was 56 years (range 27-79 years), and the male-to-female ratio was 2.54 to 1 . Detailed information is listed in Table I.

TRM staging system. According to the commonly used cut-off approach by the log-rank test, three cut-off points were generated: $0,0.50$ and 0.80 . According to X-tile (http://www. tissuearray.org/rimmlab/), patients with $\mathrm{LNR}=0$ were fixed into one group, as it has been demonstrated that their prognosis was significantly different from patients with LNR $>0$ (20). The remaining patients were analyzed and the two other cut-off points were 0.48 and 0.79 . Considering the log-rank test results and clinical feasibility, the final cut-off points for LNR were set as $0,0.5$ and 0.8 . Four subgroups were then determined $(\mathrm{R} 0, \mathrm{LNR}=0 ; \mathrm{R} 1, \mathrm{LNR} \leq 0.5 ; \mathrm{R} 2,0.5>\mathrm{LNR} \leq 0.8$; and R3, LNR >0.8), and the TRM staging system was generated. Compared with the 7th AJCC TNM staging system, 55 $(39.9 \%)$ GC patients were downstaged and no patients were upstaged in the TRM staging system (Fig. 1).

Correlations between the number of removed LNs, $p N$ and $L N R$. There was a significant correlation between the number of removed LNs and $\mathrm{pN}(\mathrm{r}=0.228, \mathrm{P}=0.001)$ (Fig. 2A). There was no significant correlation between the number of removed LNs and LNR ( $\mathrm{r}=0.019, \mathrm{P}=0.825$ ) (Fig. 2B). The difference between $\mathrm{pN}$ and LNR was statistically significant $(\mathrm{r}=0.931$, $\mathrm{P}<0.001$ ) (Fig. 2C). These results demonstrated that LNR was not influenced by surgery; however, $\mathrm{pN}$ was.

Univariate and multivariate analyses. By the Kaplan-Meier curve and log-rank test, nine factors were identified as possible determinants on overall survival (OS), including cancer site $(\mathrm{P}=0.020)$, tumor invasion $(\mathrm{P}=0.004), \mathrm{pN}(\mathrm{P}<0.001), \mathrm{LNR}$ $(\mathrm{P}<0.001)$, distant metastases $(\mathrm{P}<0.001)$, TNM staging $(\mathrm{P}<0.001)$, TRM staging $(\mathrm{P}<0.001)$, surgery type $(\mathrm{P}=0.044)$ and postoperative serious adverse events (SAEs) $(\mathrm{P}<0.001)$. All factors were then integrated into multivariate analysis using Cox proportional hazards model, and both LNR and $\mathrm{pN}$ were found to be independent prognostic factors (Table II).

Comparison of the discriminative power between $p N$ and LNR for OS. The median OS of R0, R1, R2 and R3 was 64.4 months [95\% confidence interval (CI), 50.9-77.9 months], 37.8 months (95\% CI, 19.6-56.0 months), 13.8 months (95\% CI, 6.4-21.2 months) and 7.5 months (95\% CI, 2.2-12.7 months), respectively ( $\mathrm{P}<0.001$, overall comparison; $\mathrm{P}=0.071$ for $\mathrm{R} 0$ vs. $\mathrm{R} 1 ; \mathrm{P}<0.001$ for $\mathrm{R} 1$ vs. $\mathrm{R} 2$; and $\mathrm{P}=0.001$ for R2 vs. R3) (Fig. 3A). In comparison, the median OS of N0, $\mathrm{N} 1, \mathrm{~N} 2$ and N3 was 64.4 months (95\% CI, 50.9-77.9 months), 61.5 months (95\% CI, 44.4-78.6 months), 27.0 months (95\% CI, 
Table I. The characteristics and univariate analysis of 138 patients with GC.

\begin{tabular}{|c|c|c|c|c|}
\hline Variables & $\mathrm{n}(\%)$ & Events (\%) & $\begin{array}{c}\text { Median OS }(95 \% \mathrm{CI}) \\
\text { (months) }\end{array}$ & P-value \\
\hline Hospital & & & & 0.374 \\
\hline Zhongnan Hospital & $53(38.4)$ & $34(64.2)$ & $25.0(15.4-34.6)$ & \\
\hline Heji Hospital & $43(31.2)$ & $21(48.4)$ & $38.9(35.0-42.8)$ & \\
\hline Hubei Tumor Hospital & $42(30.4)$ & $21(50.0)$ & $34.1(27.8-40.4)$ & \\
\hline Gender & & & & 0.171 \\
\hline Male & $99(71.7)$ & $52(52.5)$ & $36.4(25.8-47.0)$ & \\
\hline Female & $39(28.3)$ & $24(61.5)$ & $27.0(16.3-37.7)$ & \\
\hline Age (years) & & & & 0.216 \\
\hline$\leq 65$ & $101(73.2)$ & $52(51.5)$ & $36.4(17.5-55.3)$ & \\
\hline$>65$ & $37(26.8)$ & $24(64.9)$ & $25.0(16.1-33.9)$ & \\
\hline Cancer site & & & & 0.020 \\
\hline Upper third & $31(22.5)$ & $14(45.2)$ & $31.1(25.6-36.5)$ & \\
\hline Middle third & $27(19.6)$ & $15(55.6)$ & $25.0(10.9-39.1)$ & \\
\hline Lower third & $70(50.7)$ & $39(55.7)$ & $36.4(25.3-47.5)$ & \\
\hline Whole stomach & $10(7.2)$ & $8(80.0)$ & $8.7(4.1-13.4)$ & \\
\hline Pathological type & & & & 0.126 \\
\hline Intestinal & $106(76.8)$ & $57(53.8)$ & $35.9(25.7-46.1)$ & \\
\hline Diffuse & $12(8.7)$ & $5(41.7)$ & $25.9(19.3-32.4)$ & \\
\hline Mixed & $20(14.5)$ & $14(70.0)$ & $14.1(8.2-20.0)$ & \\
\hline Surgery type & & & & 0.044 \\
\hline Proximal gastrectomy & $36(26.1)$ & $16(44.4)$ & $30.7(25.4-36.0)$ & \\
\hline Distant gastrectomy & $81(58.7)$ & $44(54.3)$ & $36.4(25.6-47.2)$ & \\
\hline Total gastrectomy & $21(15.2)$ & $16(76.2)$ & $13.4(1.9-24.9)$ & \\
\hline Tumor invasion & & & & 0.004 \\
\hline $\mathrm{T} 1$ & $6(4.3)$ & $2(33.3)$ & $43.5(26.3-60.7)$ & \\
\hline $\mathrm{T} 2$ & $21(15.2)$ & $4(19.0)$ & $75.0(61.3-88.8)$ & \\
\hline $\mathrm{T} 3$ & $1(0.7)$ & $1(100.0)$ & $15.8(15.8-15.8)$ & \\
\hline $\mathrm{T} 4 \mathrm{a}$ & $79(57.2)$ & $48(60.8)$ & $28.2(16.7-39.7)$ & \\
\hline $\mathrm{T} 4 \mathrm{~b}$ & $31(22.5)$ & $21(67.7)$ & $17.5(10.4-24.6)$ & \\
\hline $\mathrm{pN}$ & & & & $<0.001$ \\
\hline N0 & $33(23.9)$ & $10(30.3)$ & $64.4(50.9-77.9)$ & \\
\hline N1 & $19(13.8)$ & $7(36.8)$ & $61.5(44.4-78.6)$ & \\
\hline $\mathrm{N} 2$ & $25(18.1)$ & $14(56.0)$ & $27.0(15.4-38.6)$ & \\
\hline N3 & $61(44.2)$ & $45(73.8)$ & $14.6(8.4-20.8)$ & \\
\hline LNR & & & & $<0.001$ \\
\hline R0 & $33(23.9)$ & $10(30.3)$ & $64.4(50.9-77.9)$ & \\
\hline R1 & $68(49.3)$ & $34(50.0)$ & $37.8(19.6-56.0)$ & \\
\hline $\mathrm{R} 2$ & $24(17.4)$ & $19(79.2)$ & $13.8(6.4-21.2)$ & \\
\hline R3 & $13(9.4)$ & $13(100.0)$ & $7.5(2.2-12.7)$ & \\
\hline Distant metastases & & & & $<0.001$ \\
\hline M0 & $128(92.8)$ & $66(51.6)$ & $36.4(27.8-45.0)$ & \\
\hline M1 & $10(7.2)$ & $10(100.0)$ & $11.4(7.6-15.1)$ & \\
\hline TNM staging & & & & $<0.001$ \\
\hline I & $18(13.0)$ & $3(16.7)$ & $77.2(63.4-91.0)$ & \\
\hline II & $19(13.8)$ & $7(36.8)$ & $43.4(32.3-54.5)$ & \\
\hline IIIA & $17(12.3)$ & $6(35.3)$ & $64.5(47.7-81.3)$ & \\
\hline IIIB & $15(10.9)$ & $9(60.0)$ & $28.0(25.0-31.0)$ & \\
\hline IIIC & $61(44.2)$ & $43(70.5)$ & $14.6(8.6-20.5)$ & \\
\hline IV & $8(5.8)$ & $8(100.0)$ & $11.4(2.1-20.7)$ & \\
\hline
\end{tabular}


Table I. Continued.

\begin{tabular}{lccc} 
Variables & $\mathrm{n}(\%)$ & Events $(\%)$ & $\begin{array}{c}\text { Median OS (95\% CI) } \\
\text { (months) }\end{array}$ \\
\hline TRM staging & & & \\
I & $18(13.0)$ & $3(16.7)$ & $77.2(63.4-91.0)$ \\
II & $20(14.5)$ & $7(35.0)$ & $44.3(33.4-55.1)$ \\
IIIA & $40(29.0)$ & $21(52.5)$ & $36.4(4.3-68.5)$ \\
IIIB & $32(23.2)$ & $17(53.1)$ & $25.0(10.1-39.9)$ \\
IIIC & $20(14.5)$ & $20(100.0)$ & $11.3(9.1-13.5)$ \\
IV & $8(5.8)$ & $8(100.0)$ & $11.4(2.1-20.7)$
\end{tabular}

Postoperative SAE

$\begin{array}{lrr}\text { No } & 118(85.5) & 57(48.3) \\ \text { Yes } & 20(14.5) & 19(95.0)\end{array}$

$38.9(20.7-57.1)$

$13.4(5.9-20.9)$

Chemotherapy
No
$52(37.7)$
$31(59.6)$
$23.5(14.5-32.5)$
Yes
$86(62.3)$
$45(52.3)$
$37.8(22.2-53.4)$

GC, gastric cancer; CI, confidence interval; pN, lymph node status; LNR, lymph node ratio; TNM staging, tumor-node-metastases staging; TRM staging, tumor-node-ratio-metastases staging; SAE, serious adverse event; OS, overall survival.

A

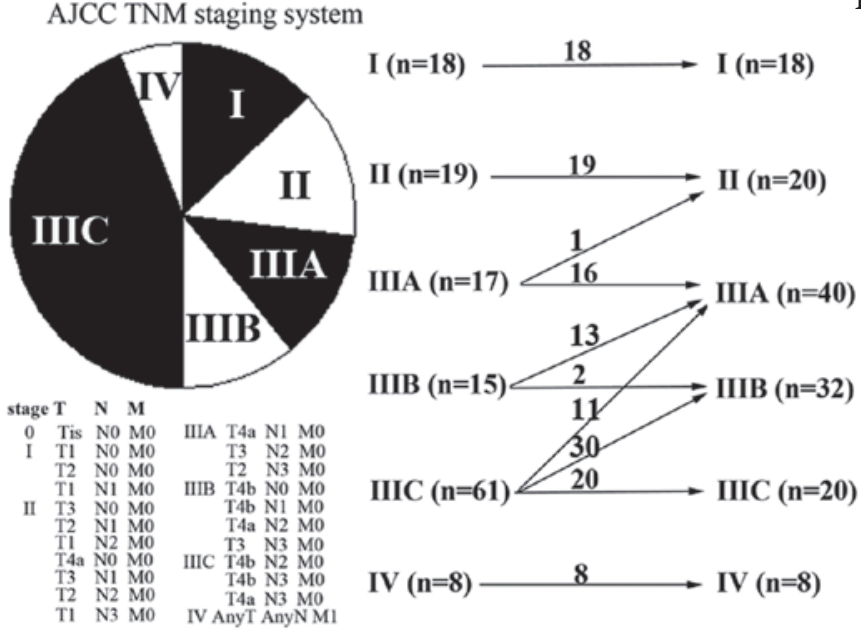

B TRM staging system

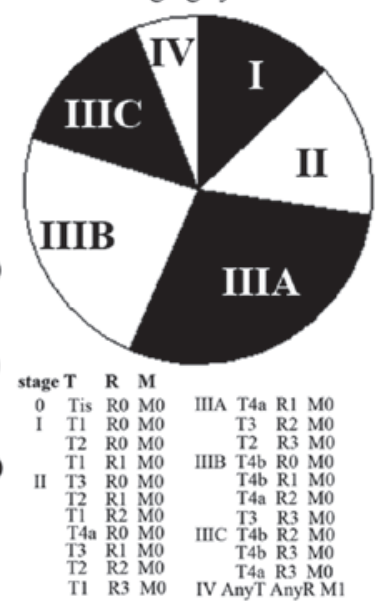

Figure 1. Patient distribution in the 7th American Joint Committee on Cancer (AJCC) (A) tumor-node-metastases (TNM) staging system and (B) tumor-node-ratio-metastases (TRM) staging system. Compared with the 7th AJCC TNM staging system, 55 (39.9\%) GC patients were downstaged and no patients were upstaged in the TRM staging system.
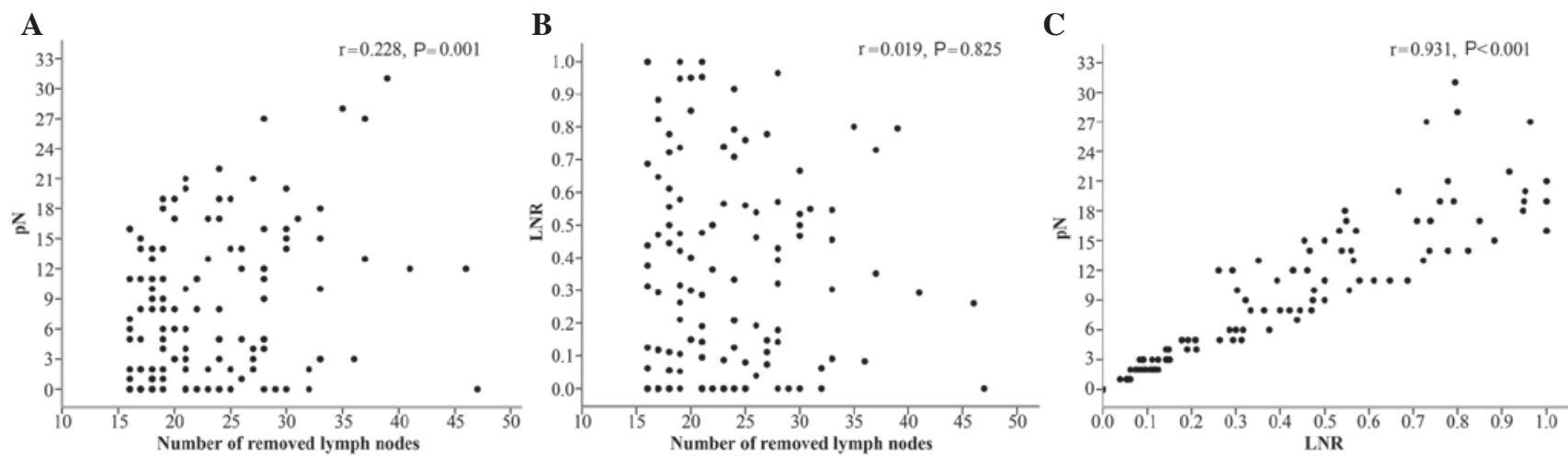

Figure 2. Pearson's correlation tests. (A) Significant correlation between the number of removed lymph nodes (LNs) and lymph node status (pN), (B) Non-significant correlation between the number of removed LNs and lymph node ratio (LNR). (C) Significant correlation between pN and LNR. 
A

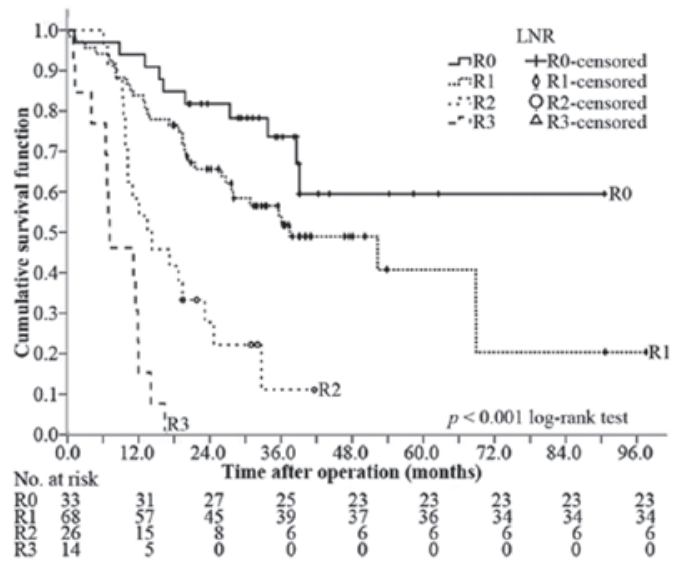

B

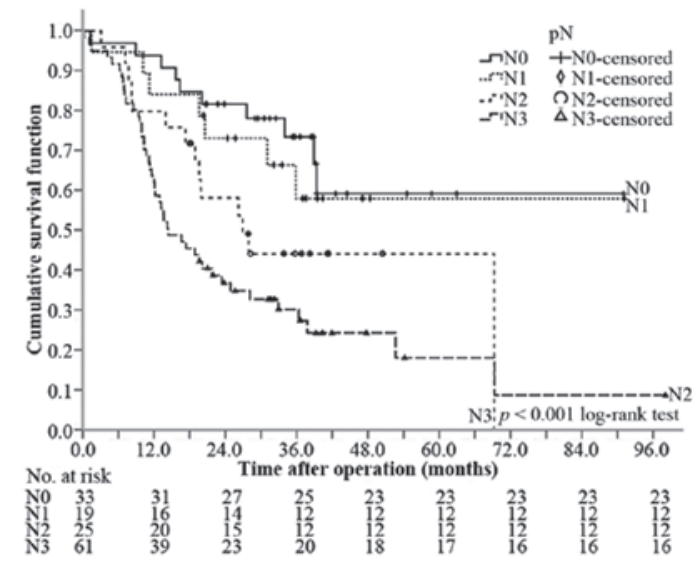

Figure 3. Kaplan-Meier survival curves, classified by (A) lymph node ratio (LNR) and (B) lymph node status (pN). The LNR could better divide the patients into four different groups than $\mathrm{pN}$.

A

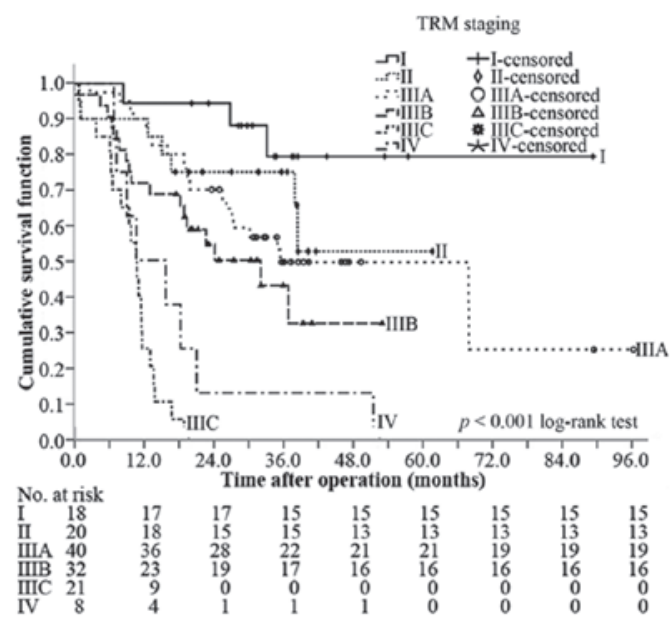

B

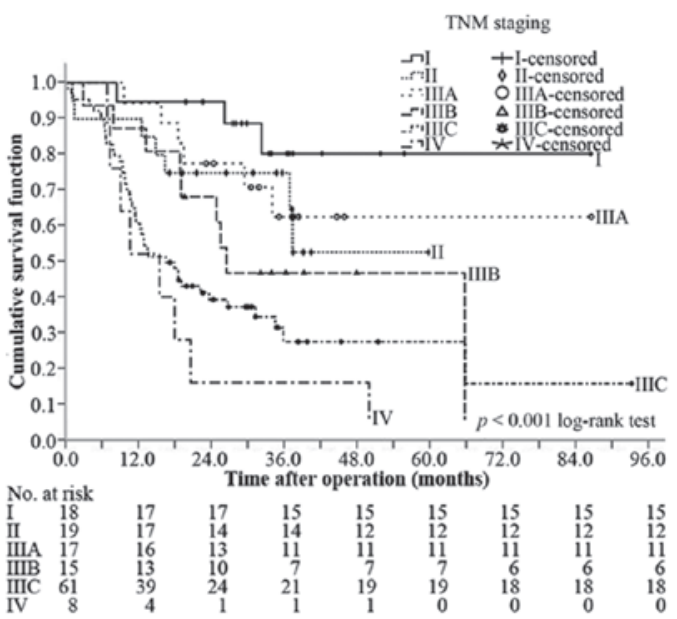

Figure 4. Kaplan-Meier survival curves, classified by (A) tumor-node-ratio-metastases (TRM) staging, and (B) tumor-node-metastases (TNM) staging. The TRM staging could better divide the patients into six different groups than the TNM staging. Censored patients were alive at the time of the most recent follow-up and their survival-time was recorded as the last follow-up date.

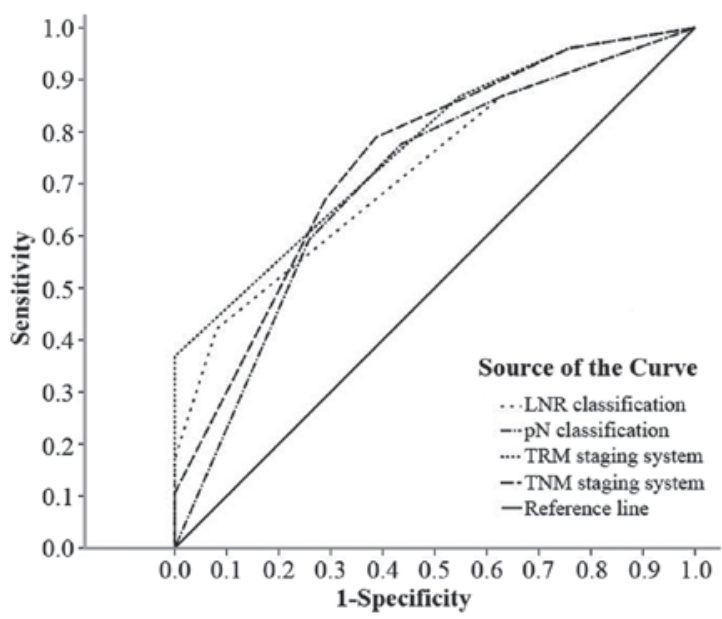

Figure 5. Predictive values of lymph node status (pN) classification, lymph node ratio (LNR), 7th American Joint Committee on Cancer (AJCC) tumor-node-metastases (TNM) staging system and tumor-node-ratio-metastases (TRM) staging system. The TRM staging system could better predict the clinical outcomes compared with the TNM staging system, and LNR was better than $\mathrm{pN}$.
15.4-38.6 months) and 14.6 months (95\% CI, 8.4-20.8 months), respectively $(\mathrm{P}<0.001$, all overall comparison; $\mathrm{P}=0.597$ for $\mathrm{N} 0$ vs. $\mathrm{N} 1 ; \mathrm{P}=0.168$ for $\mathrm{N} 1$ vs. N2; $\mathrm{P}=0.122$ for $\mathrm{N} 2$ vs. N3) (Fig. 3B). Therefore, LNR could better differentiate OS than LN.

Comparison of the discriminative power between TRM staging and TNM staging for OS. At the median follow-up of 38.3 months (range, 9.9-97.7 months), the median OS was 23.9 months (95\% CI, 18.8-29.0 months), and the 1-, 2-, 3- and 5-year survival rates were 76.8, 57.2, 50.0 and 46.4\%, respectively. Based on the TRM staging, the median OS of stages I, II, IIIA, IIIB, IIIC and IV was 77.2 months (95\% CI, 63.4-91.0 months), 44.3 months (95\% CI, 33.4-55.1 months), 36.4 months (95\% CI, 4.3-68.5 months), 25.0 months (95\% CI, 10.1-39.9 months), 11.3 months (95\% CI, 9.1-13.5 months) and 11.4 months (95\% CI, 2.1-20.7 months), respectively $(\mathrm{P}<0.001$, overall comparison; $\mathrm{P}=0.228$ for I vs. II; $\mathrm{P}=0.490$ for II vs. IIIA; $\mathrm{P}=0.173$ for IIIA vs. IIIB; $\mathrm{P}<0.001$ for IIIB vs. IIIC, 
Table II. Independent prognostic factors of 138 GC patients identified by multivariate analysis.

\begin{tabular}{|c|c|c|c|}
\hline Variables & $\chi^{2}$ & Hazard ratio $(95 \% \mathrm{CI})$ & P-value \\
\hline \multicolumn{4}{|l|}{ TNM-based } \\
\hline $\mathrm{pN}$ & & & 0.004 \\
\hline \multicolumn{4}{|l|}{ N0 (reference) } \\
\hline N1 & 0.356 & $1.342(0.510-3.531)$ & 0.551 \\
\hline $\mathrm{N} 2$ & 4.022 & $2.301(1.019-5.193)$ & 0.045 \\
\hline N3 & 11.120 & $3.319(1.640-6.718)$ & 0.001 \\
\hline Postoperative SAE & & & 0.014 \\
\hline \multicolumn{4}{|l|}{ No (reference) } \\
\hline Yes & 6.034 & $1.991(1.149-3.449)$ & \\
\hline \multicolumn{4}{|l|}{ TRM-based } \\
\hline LNR & & & $<0.001$ \\
\hline \multicolumn{4}{|l|}{ R0 (reference) } \\
\hline $\mathrm{R} 1$ & 2.515 & $1.775(0.873-3.609)$ & 0.113 \\
\hline R2 & 18.771 & $5.636(2.578-12.321)$ & $<0.001$ \\
\hline R3 & 34.116 & $15.113(6.076-37.591)$ & $<0.001$ \\
\hline Distant metastases & & & 0.006 \\
\hline \multicolumn{4}{|l|}{ No (reference) } \\
\hline Yes & 7.685 & $2.728(1.342-5.548)$ & \\
\hline
\end{tabular}

GC, gastric cancer; CI, confidence interval; pN, lymph node status; SAE, serious adverse event; LNR, lymph node ratio.

Table III. Predictive value of the factors assessed in ROC analysis.

\begin{tabular}{|c|c|c|c|c|c|}
\hline \multirow[b]{2}{*}{ Staging systems } & \multirow[b]{2}{*}{ AUC } & \multicolumn{2}{|c|}{$95 \% \mathrm{CI}$} & \multirow[b]{2}{*}{ Std. error } & \multirow[b]{2}{*}{ P-value } \\
\hline & & Lower & Upper & & \\
\hline TRM staging system & 0.769 & 0.692 & 0.845 & 0.039 & $<0.001$ \\
\hline TNM staging system & 0.745 & 0.662 & 0.827 & 0.042 & $<0.001$ \\
\hline LNR classification & 0.724 & 0.641 & 0.807 & 0.042 & $<0.001$ \\
\hline pN classification & 0.704 & 0.615 & 0.792 & 0.045 & $<0.001$ \\
\hline
\end{tabular}

ROC, receiver operating characteristic; AUC, area under the curve; CI, confidence interval; Std. error, standard error; TRM staging, tumor-node ratio-metastases staging; TNM staging, tumor-node-metastases staging; LNR, lymph node ratio; pN, lymph node status.

Table IV. Information on LNR from previous studies and the present study.

\begin{tabular}{|c|c|c|c|c|}
\hline Authors (ref.) & No. of patients & $\begin{array}{l}\text { No. of removed LNs } \\
\text { (range) }\end{array}$ & $\begin{array}{l}\text { Cutoff points } \\
\text { of LNR }\end{array}$ & $\begin{array}{l}\text { 5-year survival rates } \\
\text { of R0, R1, R2, R3 (\%) }\end{array}$ \\
\hline Kim et al (19) & 529 & $6^{a}(1-104)$ & $0,0.30,0.60$ & $71.7,35.7,16.3,0$ \\
\hline Asoglu et al (20) & 264 & $27^{\mathrm{b}}(16-75)$ & $0,0.10,0.25$ & $86.9,81.1,47.1,24.7$ \\
\hline $\mathrm{Xu}$ et al (21) & 177 & $20^{\mathrm{a}}(16-53)$ & $0,0.10,0.25$ & $84.3,71.1,45.1,24.2$ \\
\hline Lee et al (22) & 342 & $28.9^{\mathrm{b}}(16-98)$ & $0,0.30,0.60$ & Unknown \\
\hline Huang et al (23) & 634 & $23^{\mathrm{a}}(5-61)$ & $0,0.20,0.50$ & $83.3,68.4,40.7,17.2$ \\
\hline Feng et al (24) & 109 & $38.34^{\mathrm{b}}$ & $0,0.10,0.25$ & $58.8,43.8,25.0,10.4$ \\
\hline Lemmens et al (25) & 880 & $7^{\text {a }}$ (unknown) & $0,0.20,0.30$ & $58,50,18,11$ \\
\hline Wang et al (16) & 1343 & $15^{\mathrm{b}}(3-72)$ & $0,0.30,0.60$ & $77.5,64.3,39.7,22.3$ \\
\hline Qiu et al (26) & 730 & $16^{\mathrm{a}}(0-72)$ & $0,0.30,0.60$ & $72.1,65.6,30.3,13.0$ \\
\hline Present study & 138 & $21^{\mathrm{a}}(16-47)$ & $0,0.50,0.80$ & $69.7,52.9,20.8,0$ \\
\hline
\end{tabular}

${ }^{\mathrm{a}}$ Median number of removed LNs; ${ }^{b}$ mean number of removed LNs. LNR, lymph node ratio; LN, lymph node. 
$\mathrm{P}=0.072$ for IIIC vs. IV) (Fig. 4A). By comparison, the median OS of stages I, II, IIIA, IIIB, IIIC and IV of TNM staging was 77.2 months (95\% CI, 63.4-91.0 months), 43.4 months (95\% CI, 32.3-54.5 months), 64.5 months (95\% CI, 47.7-81.3 months), 28.0 months (95\% CI, 25.0-31.0 months), 14.6 months (95\% CI, 8.6-20.5 months) and 11.4 months (95\% CI, 2.1-20.7 months), respectively $(\mathrm{P}<0.001$, overall comparison; $\mathrm{P}=0.190$ for I vs. II; $\mathrm{P}=0.786$ for II vs. IIIA; $\mathrm{P}=0.180$ for IIIA vs. IIIB; $\mathrm{P}=0.181$ for IIIB vs. IIIC, $\mathrm{P}=0.212$ for IIIC vs. IV) (Fig. 4B). TRM staging was capable of discriminating stages IIIB and IIIC, but TNM staging could not discriminate any neighboring subgroups.

Predictive accuracy. The predictive value of the LNR classification, pN classification, TRM staging system and TNM staging system was further studied by ROC analysis. All of the factors predicted mortality precisely $(\mathrm{P}<0.01)$ (Table III). The TRM staging system was better to predict the clinical outcomes than the TNM staging system, and LNR was better than pN (Fig. 5).

\section{Discussion}

Due to the shortcomings of the AJCC TNM staging system, increasing numbers of investigators have shifted their attention to looking for an optimal method. The most popular and the most recognized optimal method was the TRM staging system based on LNR. Table IV lists a number of previous studies on LNR, and these studies confirmed the superiority of the LNR and TRM staging system compared with the AJCC TNM staging system through univariate and multivariate analysis and Kaplan-Meier survival curves (8). In the present study, the cut-off points were $0,0.50$ and 0.80 .

In our previous study of GC, patients with stage IIIB and beyond had much poorer OS than other patients. In this study, stage IIIB and beyond accounted for $>60 \%$ of patients in TNM staging, but $<45 \%$ in TRM staging, as 24 (17.4\%) patients were downstaged to stage IIIA. The prognosis of patients with different classifications could apparently be discriminated, and this may provide a basis for determining secondary treatment.

In routine clinical practice, $\mathrm{LN}$ resection in $\mathrm{GC}$ patients is generally not up to D2 lymphadenectomy standard, despite D2 lymphadenectomy being regarded as the standard surgical technique in Eastern Asian countries $(21,22)$. Certain studies did not consider this factor in the inclusion criteria $(17,23,27,30)$, weakening the credibility of the results. In this study, only patients with $>15 \mathrm{LN}$ resections were included. However, $\mathrm{pN}$ is correlated with surgery, whereas LNR is not. Therefore, in univariate and multivariate analyses, both $\mathrm{pN}$ and LNR were independent prognostic factors, indicating that LNR was closely associated with prognosis, similar to pN. Moreover, the LNR and TRM staging system could better discriminate subgroups (Figs. 3 and 4), as confirmed by other studies (17,23-27,29). From this perspective, LNR was a better prognosticator than $\mathrm{pN}$.

As to the predictive accuracy analysis, there has been no validated standard. The most commonly used methods were the area under the curve by ROC analysis, the concordance index, explained variation and a summary measure of separation (31). In this study, the TRM staging system had the maximal area under the curve by ROC, and LNR also had a bigger area than $\mathrm{pN}$.
In conclusion, LNR may be a better prognosticator than $\mathrm{pN}$ for the following reasons: i) LNR has no correlation with surgery; ii) there were $55(39.9 \%)$ GC patients down-staged and no patients upstaged in the TRM staging system; iii) in univariate and multivariate analysis, both LNR and pN were independent prognostic factors; iv) the LNR and TRM staging system were capable of better differentiating patients than the $\mathrm{pN}$ and TNM staging system; v) in ROC analysis, the LNR and TRM staging system have a greater area than the $\mathrm{pN}$ and TNM staging system, respectively. The resulting TRM staging system may better predict the clinical outcomes.

\section{Acknowledgements}

This study is supported by the Academic Award for Excellent PhD Candidates Funded by the Ministry of Education of China (no. 5052011303014), the Science Fund of the National Natural Science Foundation of China (no. 81171396), the Science Fund for Creative Research Groups of the National Natural Science Foundation of China (nos. 20621502, 20921062) and the Fundamental Research Funds for the Central Universities of Ministry of Education of China (no. 4103005).

\section{References}

1. Jemal A, Bray F, Center MM, Ferlay J, Ward E and Forman D: Global cancer statistics. CA Cancer J Clin 61: 69-90, 2011.

2. Ferlay J, Shin HR, Bray F, Forman D, Mathers C and Parkin DM: Estimates of worldwide burden of cancer in 2008: GLOBOCAN 2008. Int J Cancer 127: 2893-2917, 2010.

3. Yang L: Incidence and mortality of gastric cancer in China. World J Gastroenterol 12: 17-20, 2006.

4. Hartgrink HH, Jansen EP, van Grieken NC and van de Velde CJ: Gastric cancer. Lancet 374: 477-490, 2009.

5. Wang $\mathrm{XN}$ and Liang H: Some problems in the surgical treatment of gastric cancer. Chin J Cancer 29: 369-373, 2010.

6. Viudez-Berral A, Miranda-Murua C and Arias-de-la-Vega F, et al: Current management of gastric cancer. Rev Esp Enferm Dig 104: 134-141, 2012.

7. Lee JH, Kim KM, Cheong JH and Noh SH: Current management and future strategies of gastric cancer. Yonsei Med J 53: 248-257, 2012.

8. Wu HL, Tian Q, Peng CW, Liu SP and Li Y: Multivariate survival and outcome analysis of 154 patients with gastric cancer at a single Chinese institution. Asian Pac J Cancer Prev 12: 3341-3345, 2011.

9. Landry CS, Brock G, Scoggins CR, McMasters KM and Martin RN II: A proposed staging system for gastric carcinoid tumors based on an analysis of 1,543 patients. Ann Surg Oncol 16: 51-60, 2009.

10. Cammerer G, Formentini A, Karletshofer M, Henne-Bruns D and Kornmann M: Evaluation of important prognostic clinical and pathological factors in gastric cancer. Anticancer Res 32: 1839-1842, 2012

11. Washington K: 7th edition of the AJCC cancer staging manual: stomach. Ann Surg Oncol 17: 3077-3079, 2010.

12. Sun Z, Wang ZN and Zhu Z, et al: Evaluation of the seventh edition of American Joint Committee on Cancer TNM staging system for gastric cancer: results from a Chinese monoinstitutional study. Ann Surg Oncol 19: 1918-1927, 2012.

13. Chae S, Lee A and Lee JH: The effectiveness of the new (7th) UICC N classification in the prognosis evaluation of gastric cancer patients: a comparative study between the 5th/6th and 7th UICC N classification. Gastric Cancer 14: 166-171, 2011.

14. Ahn HS, Lee HJ and Hahn S, et al: Evaluation of the seventh American Joint Committee on Cancer/International Union Against Cancer Classification of gastric adenocarcinoma in comparison with the sixth classification. Cancer 116: 5592-5598, 2010 . 
15. Wang W, Sun XW and Li CF, et al: Comparison of the 6th and 7 th editions of the UICC TNM staging system for gastric cancer: results of a Chinese single-institution study of 1,503 patients. Ann Surg Oncol 18: 1060-1067, 2011.

16. Kim SS, Choi BY, Seo SI, et al: The comparison between 6th and 7th International Union Against Cancer/American Joint Committee on Cancer Classification for Survival Prognosis of Gastric Cancer. Korean J Gastroenterol 58: 258-263, 2011 (In Korean).

17. Wang W, Xu DZ and Li YF, et al: Tumor-ratio-metastasis staging system as an alternative to the 7th edition UICC TNM system in gastric cancer after D2 resection - results of a single-institution study of 1343 Chinese patients. Ann Oncol 22: 2049-2056, 2011.

18. Wang J, Dang P and Raut CP, et al: Comparison of a lymph node ratio-based staging system with the 7th AJCC system for gastric cancer: analysis of 18,043 patients from the SEER database. Ann Surg 255: 478-485, 2012.

19. Lee SR, Kim HO, Son BH, Shin JH and Yoo CH: Prognostic significance of the metastatic lymph node ratio in patients with gastric cancer. World J Surg 36: 1096-1101, 2012.

20. Liu X, Cai H, Shi Y and Wang Y: Prognostic factors in patients with node-negative gastric cancer: a single center experience from China. J Gastrointest Surg 16: 1123-1127, 2012.

21. Diaz de Liaño A, Yarnoz C, Aguilar R, Artieda C and Ortiz $\mathrm{H}$ : Rationale for gastrectomy with D2 lymphadenectomy in the treatment of gastric cancer. Gastric Cancer 11: 96-102, 2008.

22. D'Annibale A, Pende V, Pernazza G, et al: Full robotic gastrectomy with extended (D2) lymphadenectomy for gastric cancer: surgical technique and preliminary results. J Surg Res 166: 113-120, 2011.

23. Kim CY and Yang DH: Adjustment of $\mathrm{N}$ stages of gastric cancer by the ratio between the metastatic and examined lymph nodes. Ann Surg Oncol 16: 1868-1874, 2009.
24. Asoglu O, Karanlik H and Parlak M, et al: Metastatic lymph node ratio is an independent prognostic factor in gastric cancer. Hepatogastroenterology 56: 908-913, 2009.

25. Xu DZ, Geng QR and Long ZJ, et al: Positive lymph node ratio is an independent prognostic factor in gastric cancer after $\mathrm{d} 2$ resection regardless of the examined number of lymph nodes. Ann Surg Oncol 16: 319-326, 2009.

26. Lee SY, Hwang I, Park YS, Gardner J and Ro JY: Metastatic lymph node ratio in advanced gastric carcinoma: A better prognostic factor than number of metastatic lymph nodes? Int J Oncol 36: 1461-1467, 2010.

27. Huang CM, Lin JX and Zheng CH, et al: Prognostic impact of metastatic lymph node ratio on gastric cancer after curative distal gastrectomy. World J Gastroenterol 16: 2055-2060, 2010.

28. Feng J, Wu YF, Xu HM, Wang SB and Chen JQ: Prognostic significance of the metastatic lymph node ratio in T3 gastric cancer patients undergoing total gastrectomy. Asian Pac J Cancer Prev 12: 3289-3292, 2011

29. Lemmens V, Dassen AE, van der Wurff A, Coebergh J and Bosscha K: Lymph node examination among patients with gastric cancer: variation between departments of pathology and prognostic impact of lymph node ratio. Eur J Surg Oncol 37: 488-496, 2011

30. Qiu MZ, Qiu HJ and Wang ZQ, et al: The tumor-log odds of positive lymph nodes-metastasis staging system, a promising new staging system for gastric cancer after D2 resection in China. PLoS One 7: e31736, 2012.

31. Peng CW, Wang LW, zeng WJ, Yang XJ and Li Y: Evaluation of the staging system for gastric cancer. J Surg Oncol 108: 93-105, 2013. 